\title{
Pneumocystis jirovecii Pneumonia: Epidemiology, Clinical Manifestation and Diagnosis
}

\author{
P. Lewis White ${ }^{1} \cdot$ Jessica S. Price ${ }^{1} \cdot$ Matthijs Backx ${ }^{1}$ \\ Published online: 14 September 2019 \\ (C) Springer Science+Business Media, LLC, part of Springer Nature 2019
}

\begin{abstract}
Purpose of Review The purpose of this study is to provide an understanding of the increased range of patient cohorts at risk of Pneumocystis jirovecii pneumonia (PCP) and describe typical clinical presentations together with advances in diagnostic assays and strategies.

Recent Findings The range of immuno-compromised patients at risk of PCP continues to expand. Apart from human immunodeficiency virus (HIV)-positive patients, those with solid tumours or suffering from haematological malignancy, solid organ transplant recipients or with autoimmune and inflammatory conditions receiving immuno-modulating therapies and patients diagnosed with primary immune deficiencies are all at increased risk of PCP. The clinical presentation of respiratory distress may be mild/moderate in the HIV-positive patient, but fulminant in HIV-negative. While typical clinical signs of PCP, along with underlying risk factors and the absence of alternative diagnoses, may be sufficient to commence therapy, every effort should be made to achieve a mycological diagnosis. With the advent of modern diagnostics techniques (real-time polymerase chain reaction (PCR) and (1-3)- $\beta$-D-Glucan), a laboratory-based diagnosis should always be attempted, although microscopic identification of Pneumocystis within respiratory samples remains the reference method. By combining different assays, it may be possible to both exclude and confirm PCP, without the need for invasive samples.

Summary This review will summarize the epidemiology, clinical manifestations and diagnostic options for PCP, and also briefly cover therapeutic management, the emerging issue of resistance and PCP in paediatric age group.
\end{abstract}

Keywords Pneumocystis $\cdot$ PCP $\cdot$ Diagnosis $\cdot$ Epidemiology $\cdot$ Clinical presentation

\section{Introduction}

With an ever-increasing susceptible HIV-negative population, the overall number of cases of Pneumocystis jirovecii pneumonia (PCP) continues to rise [1-6]. Patients with solid tumours or suffering from haematological malignancy, solid organ transplant recipients (SOT) or with autoimmune and inflammatory conditions receiving immunomodulating therapies (e.g. high-dose corticosteroids or anti-tumour necrosis factor (TNF) therapy) and patients

This article is part of the Topical Collection on Clinical Pathology

P. Lewis White

lewis.white@wales.nhs.uk

1 Public Health Wales Microbiology Cardiff, UHW, Heath Park, Cardiff CF14 4XW, UK diagnosed with primary immune deficiencies are at increased risk of PCP [6, 7].

The difficulties in diagnosing PCP have resulted in many cases being diagnosed on clinical suspicion [1]. Clinically, patients present with bilateral chest infection, respiratory signs of distress can be mild in the HIV-positive but typically more severe in the HIV-negative. Radiological signs are generally non-specific, but are typical of PCP, and when combined with risk-factors for PCP are usually sufficient to commence therapy (trimethoprim/sulfamethoxazole (TMP/SMX)), while a definitive diagnosis is attempted. With the advent of modern diagnostic techniques (real-time PCR and (1-3)- $\beta$-D-Glucan (BDG)), there is no reason for a laboratory-based diagnosis not being achieved, although microscopic identification of Pneumocystis within respiratory samples remains the reference method for confirming a diagnosis. Resistance to sulfabased therapies is emerging, but identifying this is difficult due to the lack of a cultured organism for susceptibility testing. However, molecular-based assays are now available to 
identify mutations in genes encoding the proteins targeted by frontline therapy and likely result in identifying resistance to therapy [8].

\section{Epidemiology of Pneumocystis Pneumonia}

In the 1980s, during the HIV pandemic, PCP was one of the most prevalent Acquired Immunodeficiency Syndrome (AIDS) defining diseases in the developed world [9]. More recently, due to the use of prophylaxis and the initiation of effective, early anti-retroviral therapy, irrespective of CD4 count, the incidence of PCP in HIV-positive patients continues to fall [10]. However, it remains a common AIDS-associated manifestation in undiagnosed HIV-positive 'late-presenters', or those not receiving on-going care for HIV, whether through individual choice/financial restrictions or as a result of the resource limitations of a particular country. The use of more aggressive immunosuppressive (e.g. cyclophosphamide, fludarabine, glucocorticoids, vincristine, rituximab, infliximab, ibrutinib, etc.) and immuno-modulatory approaches (TNF- $\alpha$ antagonists) in managing other conditions means the epidemiology of PCP is changing. In developing countries, the incidence of PCP has increased concurrently with increase in gross domestic product [11].

Solid-organ transplant recipients (risk greatest in heart and heart lung transplants, but total number of cases is highest in post-renal transplant patients, due to the frequency of this procedure), haematopoietic (allogeneic over autologous) stem cell transplant (HSCT) recipients, patients with haematological malignancy (acute leukaemia and lymphoproliferative disorders) and those with autoimmune conditions are at significant risk of infection. In Northern Ireland, the burden of PCP is greatest in the HIV-negative group (78\%), particularly cancer patients, where chemotherapy and immunosuppressive drugs were significant risk factors [2]. The day 30 all-cause mortality was $28 \%$, which usually ranges from 10 to $62 \%$, depending on the underlying condition. PCP in HIV-positive patients in England also fell between 2000 and 2010, but increased by 30 and $25 \%$ in patients with haematological malignancy and renal transplant recipients, respectively [1]. A 15-year review of PCP cases at a Korean tertiary care hospital confirmed that the number of cases was increasing annually, and was driven by cases of PCP in HIV-negative patients, with cases of PCP in HIV-positive patients actually falling [12]. Three hundred and sixty-two (85.4\%) of the 424 PCP patients were HIV-negative, $35 \%$ with haematological malignancy, $33 \%$ were SOT recipients, $15 \%$ with autoimmune disorders and $12 \%$ with solid tumours.

Patients with connective tissue disorders receiving more intensive immunosuppressive treatment and those diagnosed with ANCA-positive vasculitis (in particular granulomatosis with polyangiitis) should receive PCP prophylaxis, and this may be extended to patients with lymphopenia or with a low CD4 count post-intense immunotherapy [13]. A review of the literature for $\mathrm{PCP}$ in 18 patients treated with rituximab for auto-immune diseases other than rheumatoid arthritis showed rituximab to be a risk factor for $\mathrm{PCP}$ whether used alone or in combination with corticosteroids in patients with CD4 $>350$ / $\mu \mathrm{l}$, with a most likely onset 3-6 months post-rituximab infusion [14]. However, the incidence of PCP in 801 patients with autoimmune blistering disease was $0.1 \%$, below that recorded previously for immunosuppressed dermatology patients $(1.3 \%)$ and significantly below the recommended threshold for initiating PCP prophylaxis (3.5\%) [15].

Despite this increasing at-risk susceptible population, PCP remains relatively uncommon across most at-risk groups (incidence $<5 \%$ ), but with more patients receiving combinations of immunosuppressive therapies, the actual incidence could vary significantly $[3-5,16,17]$. The estimated incidence of PCP in the UK in SOT recipients was 5.8, 5.5, 1.2 and 0.3\% for lung/heart and lung, heart, liver and kidney transplants, respectively [3]. The global incidence of PCP in patients with haematological malignancy post-allogeneic and autologous stem cell transplantation between 1995 and 2005 was 0.63 and $0.28 \%$, respectively [5]. The incidence of PCP in the USA in HIV-infected patients over the last decade was $0.7 \%$ [4].

The timing of PCP onset can vary. In HIV-positive patients presenting with PCP as an AIDS defining disease, it is not possible to predict how long that patient has been at risk for PCP (i.e. how long the patient has had CD4 <200). However, in patients with haematological malignancy, post-HSCT, it is known that disease can occur between 5 and 587 days postHSCT, with $50 \%$ of patients presenting between 60 and 270 days after allogeneic transplant [5]. In renal transplant recipients, the risk period is greatest 12 months post-transplant, but cases have been documented much later than this period [16] In a Swiss study of 2842 SOT recipients, the mean onset was 493 days post-transplantation, and early onset was associated with the lack of PCP prophylaxis [17]. The broad duration of possible PCP onset post-HSCT can make it difficult to initiate or maintain prophylaxis post-transplant [18].

\section{Clinical Manifestation}

In all cohorts, the symptoms of PCP are generally non-specific and are typically indicative of pneumonia. Extra-pulmonary disease is rare. The underlying condition of the patients, their immune status and other potential risk factors heightens suspicions of the disease, especially when other more typical bacterial and viral pathogens have been excluded. Symptoms include fever, non-productive cough, worsening chest pain and dyspnoea (particularly on physical exertion). Dyspnoea and cough can be less evident in the HIV-negative 
[10]. Hypoxia and respiratory failure can occur, particularly in the HIV-negative patients, and mechanical ventilation may be required to manage fulminant disease, associated with lower fungal burden but a strong immune response, leading to severe symptoms within days. In certain HIV-negative populations (e.g. patients with haematological malignancy), management of PCP in an intensive care unit (ICU) is recommended [19]. In HIV-positive patients, PCP usually presents as a progressive deterioration over a period of weeks despite typically being associated with a significant respiratory burden [7]. In a comparison of HIV-negative rheumatology patients $(n=25)$ with HIV-negative connective tissue disorders $(n=10)$, the onset of PCP was significantly later in rheumatology patients (132 vs. 19 months) [20].

Depending on the presenting symptoms and blood oxygen levels, PCP can be stratified into mild, moderate (typically in HIV-positive) or severe disease. Mild disease presents with dyspnoea on exertion, with a resting arterial oxygen tension $\left(\mathrm{PaO}_{2}\right)$ of $>11.0 \mathrm{kPa}$, oxygen saturation $\left(\mathrm{SaO}_{2}\right)>96 \%$, with normal or minimal changes on chest X-ray [21]. Moderate disease presents with dyspnoea on minimal exertion, possibly at rest, fever, $\mathrm{a} \mathrm{PaO}_{2} 8.1-11.0 \mathrm{kPa}, \mathrm{SaO}_{2}$ of $91-96 \%$ and diffuse interstitial changes on chest $\mathrm{X}$-ray. During severe disease, there is dyspnoea and tachypnea at rest, with fever and cough, $\mathrm{PaO}_{2}$ is below $8.0 \mathrm{kPa}$ and $\mathrm{SaO}_{2}$ is below $91 \%$, and chest radiography usually demonstrating extensive interstitial changes with a potential for diffuse alveolar shadowing [21]. The classification of disease severity is generally applicable regardless of the patient's predisposing underlying condition $[19,21]$.

For certain populations (HIV-positive, haematological malignancy, SOT), risk factors associated with PCP are well described (e.g. CD4 count $<200 / \mu$ l, graft-versushost disease (GVHD), corticosteroids), but are continually amended due to the increasing diversity of the susceptible population and advances in the treatment of the underlying condition [7, 22-24]. In the study of 362 HIVnegative patients, previous steroid treatment was used in $95 \%$ of patients with a range of underlying conditions [12]. The mean CD4 counts were approximately sixfold higher in the HIV-negative group. A longer administration of high-dose steroids ( $\geq 20 \mathrm{mg} /$ day for $\geq 3$ weeks) was a risk factor for PCP in patients with underlying lung cancer [25]. Treatment of solid cancer with radiotherapy and/or combined chemo-radiotherapy and lymphopenia were more common in PCP patients [12]. In a study comparing patients with rheumatological disease and patients with connective tissue disorders, the former received less glucocorticoids but more methotrexate [20].

In recipients of kidney and/or kidney/pancreas transplants, cytomegalovirus (CMV) viremia (median viral load $3685 \mathrm{IU} /$ $\mathrm{ml}$ ) was a risk factor for PCP, with $90 \%$ of patients having CMV 1 year prior to PCP and $89 \%$ had active CMV infection when diagnosed with PCP [26]. The association with CMV was not seen in HSCT patients, where lymphopenia, acute graft-versus-host disease and the use of immunosuppressive agents were significantly associated with PCP post-allogeneic HSCT [5].

A meta-analysis of risk-factors associated with increased mortality from PCP include age, sex, delay in diagnosis, respiratory failure, solid tumours, high lactate dehydrogenase (LDH), low serum albumin and bacterial, Aspergillus or CMV co-infection [24]. Other prognostic markers have been described in both HIV-positive and HIV-negative cohorts [27, 28].

Computerized tomography (CT) is the optimal radiological investigation to assist in the diagnosis of PCP and should be considered in the early stages of the disease, even if chest X-rays are normal [29]. Using CT of the chest, PCP typically presents as bilateral ground glass opacification (GGO) with a central distribution, but mosaic and diffuse GGO can occur. Early PCP can present with diffuse GGO, which progresses to GGO and patchy consolidation, with predominant consolidations in the latter stages of disease [29]. A recent study of PCP lung cancer cases found that $67 \%$ of patients had diffuse interstitial infiltrates on radiograph, whereas CT showed more typical bilateral GGO in $66 \%$ of patients [25]. Other findings include nodules, cystic lesions, pneumothorax and pneumomediastinum, while cavities and unilateral presentation can occasionally occur $[10,22,30]$. A normal CT may be useful for excluding PCP, particularly in HIV-positive patients [31, 32]. Recently, PCP granulomatous disease was described in a HIV-positive patient who presented, 6 months post-initial successful treatment for PCP, with consolidating lung lesions caused by bronchial obstructions, possibly a result of granulomatous immune reconstitution inflammatory syndrome (IRIS) in response to persistent PCP antigens [33].

While certain radiological evidence (e.g. bilateral GGO) may be typical of PCP in certain populations, they may vary dependent on the HIV status [10]. However, no radiological findings are specific to PCP and are therefore not pathognomonic and efforts should be made to achieve a mycological diagnosis; however, treatment of high-risk cohorts should be initiated while awaiting results. In rheumatoid patients, interstitial lung disease may be a result of rheumatoid arthritis, methotrexate use or PCP and these factors can be additive or even synergistic for interstitial lung injury, the symptoms and radiology of which is very similar to PCP [34]. In a HIVpositive PCP patient, CT chest demonstrated diffuse nodular opacities and not GGO, and clinicians should not be reliant on the expected radiology when managing possible cases [35]. The recent review by Cereser and colleagues provides an excellent overview of the typical radiology, but also the alternative causes in HIV-negative patients [36•]. 


\section{Diagnosis}

When PCP is clinically suspected, treatment should not be delayed while awaiting diagnostic confirmation. Obtaining bronchoalveolar lavage (BAL) fluid is beneficial, and negativity, particularly by PCR, can be used to exclude PCP, but the specimen can also be investigated for other infections. The incorporation of non-classical mycological investigations (e.g. BDG) has permitted the testing of less invasive specimens. It is important to consider the impact of the available fungal burden on test performance. In HIV-positive patients, burdens will be high and subsequent sensitivity should be optimal, irrespective of the test format. In symptomatic HIV-negative patients, burden will invariably be less and this can impact negatively on assay sensitivity. In rheumatoid arthritis patients with PCP, a potential lower fungal burden results in reduced PCP PCR positivity, lower plasma BDG and serum LDH concentrations, yet higher $\mathrm{C}$-reactive protein (CRP) concentration [20]. A summary of the options and performance of the mycological and non-mycological investigations for PCP is shown in Fig. 1 and Table 1.

\section{Non-mycological Laboratory Investigations}

Being associated with lung damage, a high LDH concentration $(>500 \mathrm{mg} / \mathrm{dL})$ is a useful adjunctive test in the HIVpositive patient, where high concentrations can be associated with severe disease, but due to limited specificity every effort should be made to confirm LDH positivity with a mycological assay (microscopy, PCP PCR or BDG) [10, 45]. With a high sensitivity associated with PCP in the HIV-positive, normal LDH levels can be used to exclude PCP [45]. Outside the HIV-positive population, the use of LDH is associated with variable sensitivity (50\% in solid tumours; $89 \%$ in connective tissue disorders) and specificity (29\% in haematological malignancy; 77\% in solid tumours), and is not a useful test [45]. A recent meta-analysis of LDH accuracy for the diagnosis of PCP generated sensitivity of $80-100 \%$, dependent on underlying condition, but showed wide ranging specificity (6$85 \%$ ), and confirmed that overall performance was superior in HIV-positive patients [46].

While procalcitonin levels associated with PCP $(1.13 \mathrm{ng} / \mathrm{ml})$ can be lower than bacterial pneumonia $(19.47 \mathrm{ng} / \mathrm{ml})$ and tuberculosis (TB) $(4.16 \mathrm{ng} / \mathrm{ml})$, they are comparable to other causes of atypical pneumonia (e.g. Mycoplasma $\mathrm{sp.} 1.32 \mathrm{ng} / \mathrm{ml}$ ) [47]. Being a pro-inflammatory marker, procalcitonin levels will likely be proportional with the severity of disease. Consequently, lower concentrations could be expected in the HIV-positive patient presenting with mild disease. A recent comparison of procalcitonin and CRP to discriminate PCP from TB and bacterial pneumonia in HIVpositive patients showed that while the median concentrations for both tests differed significantly between diseases, there was considerable overlap in results, making differentiation difficult [48]. CRP may also be normal in PCP and can therefore not be used to rule out infection [10]. The optimal use of non-mycological markers will likely be as part of a multicomponent diagnostic algorithm to provide a clinical prediction strategy.

\section{Classical Mycological Investigations}

Culture of $P$. jirovecii has proven difficult and does not form part of routine diagnostic investigation. Although axenic culture of Pneumocystis is feasible, it was not possible to replicate this procedure and its application is limited to research projects $[49,50]$.

The current gold standard for confirming a diagnosis remains histological and/or microscopic identification of ascus (cysts containing ascospores) and trophic forms of Pneumocystis in clinical specimens, usually respiratory samples using conventional (Wright's-Giemsa, toluidine blue O, calcofluor white/blue or Grocott-Gomori) or immunofluorescent antibody stains. The stains can be generic (toluidine blue/ calcofluor white), not specific to Pneumocystis, staining nucleic acids or cellulose/chitin and the latter is not readily produced by Pneumocystis. Others stain the cell wall of the ascus (Grocott-Gomori stains) or the nuclei of both ascus and trophic forms (Giemsa). Standard microscopic investigation is highly subjective and this can influence specificity and sensitivity. These are dependent on the fungal burden, which will vary with underlying condition and the quality of the sampling. Immuno-fluorescent (IF)-microscopy using fluorescently labelled monoclonal antibodies targeting both ascus and trophic forms has superseded conventional microscopy and is recommended, providing superior sensitivity [51•]. In a meta-analysis comparing conventional staining and IF-microscopy the sensitivity, when testing induced sputum was significantly higher using IF-microscopy (67.1\%) than with conventional staining (43.1\%) [52]. IF-microscopy performance is more accurate when testing deeper respiratory samples (BAL fluid) as compared to upper respiratory tract samples [52].

\section{Novel Mycological Investigations}

\section{Molecular Approaches}

The development of highly sensitive, non-culture based tests has enabled laboratories to diagnose PCP more readily, but more so exclude disease when tests are negative. Metaanalytical review of PCP PCR generates excellent sensitivity $\geq 97 \%$ and the subsequent negative predictive value (NPV) $\geq 99 \%$ is sufficient to rule-out PCP when PCR is negative (Table 1) [41-43]. Despite the detection of Pneumocystis colonization, positivity readily confirms disease as shown by the 
Respiratory Sample

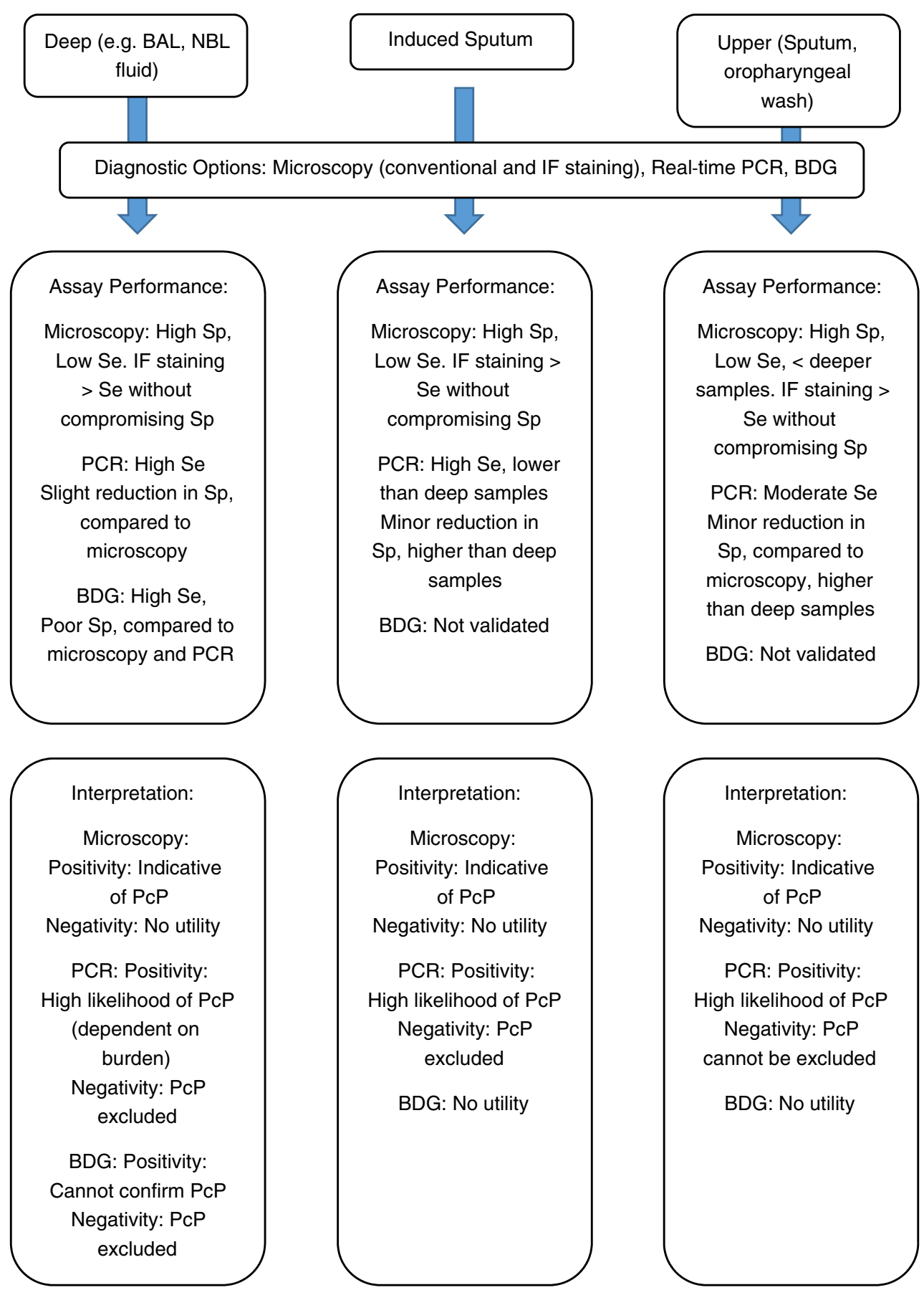

Fig. 1 a A summary of the potential diagnostic options for the investigation of respiratory samples and their associated performance, clinical interpretation and limitations for the diagnosis of Pneumocystis jirovecii pneumonia. b A summary of the potential diagnostic options for

positive likelihood ratios ( $\mathrm{LR}+\geq 10$, see Table 1$)$. While the positive predictive value (PPV) has been described as moderate, this value is significantly affected by the incidence of disease, which for PCP is low and makes obtaining a high the investigation of blood-based samples and their associated performance, clinical interpretation and limitations for the diagnosis of Pneumocystis jirovecii pneumonia

PPV difficult [53•]. PCR false-positivity is also a consequence of using sub-optimal reference methods that lack sensitivity and imply PCR false positivity that could equally be microscopy false negativity. 


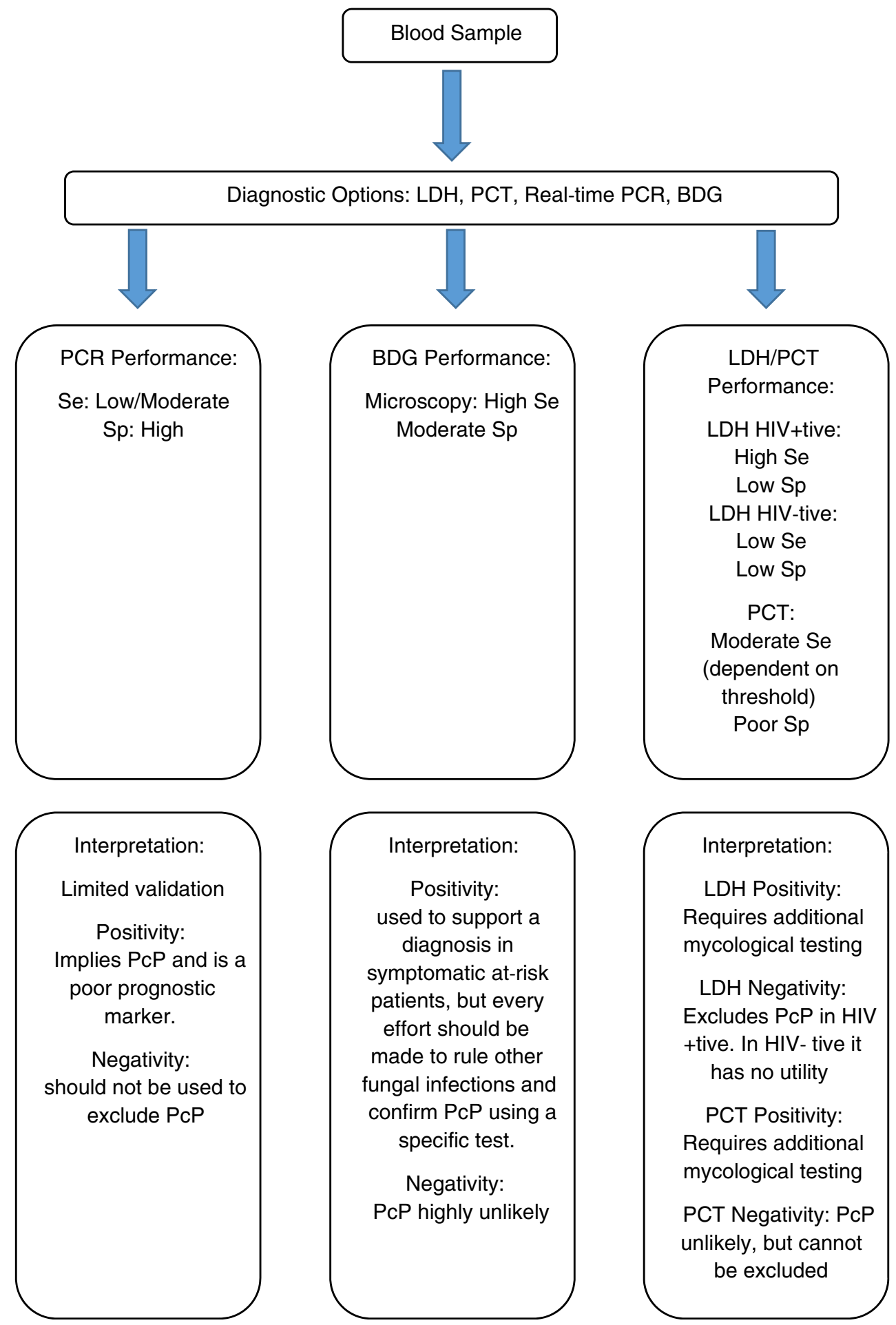

Fig. 1 (continued)

PCR testing of BAL fluid is preferred, but upper airway samples (sputum, induced sputum, oral washes and nasopharyngeal aspirates) have been tested. Positivity when testing upper airway samples was once thought to represent detection of transient colonization. It likely reflects a significant burden lower in the respiratory tract and is specific for PCP [51•]. A recent study investigated the PCR detection of Pneumocystis in oral rinses from asymptomatic HIV-positive patients; 4/100 HIV-positive patients were PCR positive, none developing PCP after 6 months, indicating that colonization needs to be considered when testing this specimen type [54]. The presence of Pneumocystis DNA in blood samples is a poor prognostic 
Table 1 Comparison of the performance of PCR and (1-3)- $\beta$-D-Glucan for the diagnosis of Pneumocystis pneumonia as derived by meta-analyses (Updated from White et al. [37])

\begin{tabular}{|c|c|c|c|c|c|c|}
\hline \multirow[t]{2}{*}{ Parameter } & \multicolumn{3}{|l|}{ (1-3)- $\beta$-D-Glucan studies } & \multicolumn{3}{|c|}{ Pneumocystis PCR studies } \\
\hline & Karageorgopoulos [38] & Onishi [39] & $\mathrm{Li}[40]$ & Summah $[41]^{\mathrm{a}}$ & Fan [42] & $\mathrm{Lu}[43]$ \\
\hline Cases/total $(\mathrm{n} / \mathrm{N})$ & $357 / 2080$ & $286 / 2331$ & $433 / 2195$ & $506 / 2330$ & $606 / 1793$ & $416 / 2505$ \\
\hline Sensitivity (\%) & 94.8 & 95.5 & 90.8 & 97 & 98 & 99 \\
\hline Specificity (\%) & 86.3 & 84.3 & 78.1 & 94 & 91 & 90 \\
\hline PPV (\%) & 54.3 & 46.0 & 50.5 & 82 & 85 & 66 \\
\hline NPV (\%) & 99.0 & 99.3 & 97.2 & 99 & 99 & $>99$ \\
\hline $\mathrm{LR}+\mathrm{ve}$ & 6.9 & 6.1 & 4.1 & 16.2 & 10.9 & 9.9 \\
\hline $\mathrm{LR}-\mathrm{ve}$ & 0.06 & 0.05 & 0.12 & 0.03 & 0.02 & 0.01 \\
\hline DOR & 115 & 122 & 34.2 & 540 & 545 & 990 \\
\hline Considerations & \multicolumn{3}{|c|}{$\begin{array}{l}\text { Multiple commercial kits available, with varying degrees in } \\
\text { validation. When positive, it is not possible to differentiate fungal } \\
\text { pathogens, although PcP typically provides high concentrations } \\
\text { ( }>500 \mathrm{pg} / \mathrm{mL} \text { ). Large number of false positive sources: } \\
\text { Semi-synthetic b-lactam antibiotics; human blood products, } \\
\text { including immunoglobulins, albumin, plasma, coagulation factor } \\
\text { infusions, filtered through cellulose membranes, cellulose } \\
\text { haemodialysis/haemofiltration membranes; exposure to (surgical) } \\
\text { gauze; bacterial bloodstream infections (e.g. Pseudomonas } \\
\text { aeruginosa) [44] }\end{array}$} & \multicolumn{3}{|c|}{$\begin{array}{l}\text { Limited methodological standardization, various gene } \\
\text { targets, DNA or DNA/RNA detection, variable positivity } \\
\text { thresholds between assays and different patient cohorts } \\
\text { makes differentiation of colonization from disease difficult } \\
\text { and often individual to centres Commercial assays } \\
\text { available, although performance is not superior to } \\
\text { 'in-house' methods } \\
\text { In the absence of culture provides the only method to detect } \\
\text { markers of resistance to sulfa-based medication associated } \\
\text { with potential treatment failures }\end{array}$} \\
\hline
\end{tabular}

${ }^{a}$ Due to incomplete information, the case and total population were calculated using sample numbers

marker. Detection of DNA in the plasma of HIV-positive patients was significantly higher in deceased patients (79\%) compared to survivors (14\%), as was the burden of the disease (deceased 54610 copies/ml vs. survivors 935 copies $/ \mathrm{ml}$ ) [55].

PCR has been used to determine prognosis. In a study of 81 HIV-negative PCP patients with respiratory failure that were initially PCR positive, weekly PCR testing was performed to determine clearance of infection and predict prognosis [56]. The overall PCR negative conversion rate was $71 \%$, taking between 1 to 2 weeks to convert. Ninetyseven percent of survivors converted compared to $64 \%$ non-survivors. By multivariate analysis, PCP PCR negative conversion was associated with a good prognosis, generating a hazard ratio of 0.433 (95\% CI $0.203-0.928$, P:0.031) [56]. However, persistent PCP PCR positivity in repeat BAL fluid is not necessarily suggestive of treatment failure [19, 57].

Nowadays, all PCR testing should be in a real-time format, allowing quantification of burden and a threshold to differentiate colonization from infection, although this might be difficult in the HIV-negative population. Fully automated PCP PCR have been developed using platforms such as the BD-MAX and GENECUBE systems, the latter generating comparable performance to the local 'in-house' real-time assay, with sensitivity and specificity of 92.3 and $85.7 \%$, respectively [58].
PCP PCR suffers from a lack of standardization. However, the Fungal PCR Initiative (working group of the International Society for Human and Animal Mycoses) is currently evaluating PCP PCR methods and together with the availability of commercial real-time assays will help address the current lack of assay standardization [59].

The application of PCR, in particular real-time PCR and fully automated systems, is not technically and financially viable for resource-limited settings where the electricity supply may be problematic, shipping of kits and reagents is complicated and technical support is limited [11]. The recent review by Guegan and Robert-Gangneux provides an excellent summary of the molecular diagnosis of PCP [53•].

The number of reports documenting PCP outbreaks is ever increasing, likely representing the increasing and prolonged susceptible population, coupled with limited infection and outbreak control guidance. Genotyping can be useful, but it is difficult to apply molecular techniques to low burdens. When performed, most outbreaks confirm a predominant strain suggesting a possibility of human-tohuman transmission but some patients with PCP were infected with multiple genotypes, hampering outbreak investigation $[60,61]$. Next-generation sequencing confirmed that PCP can be caused by a mixture of different genotypes, and outbreaks caused by a single dominant strain in renal transplant patients $[62,63]$. 


\section{Detection of (1-3)- $\beta$-D-Glucan}

BDG is a cell wall polysaccharide of most fungi, including Pneumocystis cysts that can be detected in serum/plasma using a number of commercial protease zymogen-based colorimetric assays. A recent study compared the performance of the Fungitell (well-established in the Western hemisphere) with the Wako $\beta$-glucan test (recently available in Europe) for the detection of PCP [64]. The mean BDG concentrations were markedly different (Fungitell $963 \mathrm{pg} / \mathrm{ml}$; Wako $58 \mathrm{pg}$ / $\mathrm{ml}$ ), a result of the differing reaction kinetics. The sensitivity of the Fungitell assay for PCP was 100\%, compared to $89 \%$ for the Wako assay, although this was improved to $95 \%$ by lowering the positivity threshold [64]. Another study compared these assays and confirmed the previous performance parameters, including the sensitivity benefits of reducing the positivity threshold of the Wako assay (3-4 pg/ml) [65]. The performance of the Fungitell was compared with another assay recently made available in Europe, the Dynamiker Fungus (1-3)- $\beta$-D-Glucan assay which generated sensitivity and specificity for PCP of 87 and $70 \%$, respectively, again lowering the positivity threshold $(45 \mathrm{pg} / \mathrm{ml})$ greatly improved sensitivity (96\%) [66].

While the performance of BDG assays for the detection of overall invasive fungal disease is satisfactory (Se 77\%; Sp $85 \%$ ), PCP meta-analyses of BDG provide excellent sensitivity, NPV and negative likelihood ratio of $\geq 90, \geq 97$ and $<0.12$, respectively, allowing PCP to be confidently excluded if negative [38-40,67]. BDG positivity alone is not sufficient to confirm disease. Specificity derived through meta-analyses ranges from 78 to $86 \%$, subsequent PPV and LR+tive ranging from 46 to $54 \%$ and $4.1-6.9$, respectively [38-40]. Ideally, BDG positivity should be combined with a Pneumocystisspecific assay, but this is not always feasible and positivity will often be interpreted in relation to the underlying condition and clinical presentation in the absence of an alternative diagnosis. Although BDG concentrations are typically high in patients with PCP ( $>500 \mathrm{pg} / \mathrm{ml})$, other fungal infections can provide high BDG concentrations. Conversely, to maintain a high sensitivity, a threshold of approximately $100 \mathrm{pg} / \mathrm{ml}$ is required [68]. A positive correlation between serum BDG concentrations and Pneumocystis DNA levels in BAL fluid has been shown [69].

BDG testing of BAL fluid adds little to the testing of serum, with specificity influenced by the presence of respiratory tract commensal organisms, such as Candida species or fungal colonizers [70, 71]. In a comparison of serum and BAL fluid BDG testing, sensitivity was comparable (BAL 95\%; Serum $91 \%$ ), but specificity was significantly lower when testing BAL fluid (BAL 39\%; Serum 92\%) [71]. False positivity for BDG has been widely documented (see Table 1), but also been seen in particular patient cohorts at risk of PCP. In patients with haematological malignancy and cystic fibrosis, there can be a low background level and post-haemodialysis, the concentration can be high $(>500 \mathrm{pg} / \mathrm{ml})$, and needs to be taken into consideration when evaluating results $[44,72]$. The latter of these could be explained by the fact that high rates of Pneumocystis colonization have been documented in haemodialysis patients [73]. BDG concentrations can be slow to return to normal, so determining clinical response through serial BDG monitoring is not recommended.

\section{Combination Testing and Predictive Modelling}

It is unusual for a single test to be both highly sensitive ( $>95 \%)$ and highly specific (>95\%). Indeed, high sensitivity usually compromises specificity, and vice versa. By combining multiple tests, it is hoped that disease can be confidently excluded if all tests are negative, but also confirmed if more than one test is positive. In patients with haematological malignancy, but likely applicable to most at-risk populations, the combination of IF-microscopy with PCP PCR has been proposed for the testing of BAL fluid [51•]. If both are negative, disease can be excluded, and if both are positive, PCP is confirmed. If the results are discordant, then the PCR result is favoured, which raises the question why IF-microscopy is incorporated, but reflects the current lack of standardization of both BAL fluid sampling and PCR amplification, and IFmicroscopy enhances specificity when positive. If it is not possible to obtain BAL fluid, BDG testing of serum is recommended as the front-line test, and if negative, PCP is excluded, and if positive, confirmatory PCR/IF-microscopy testing of an upper airway sample is required [51•].

BDG testing has been combined with LDH levels, using thresholds of $400 \mathrm{pg} / \mathrm{ml}$ for BDG and $350 \mathrm{U} / \mathrm{L}$ specificity for PCP was $84 \%$ [74]. Combining BDG with Krebs von den Lungen-6 antigen (KL-6, a potential marker of interstitial pneumonitis) sensitivity for PCP was $94 \%$ and specificity was $90 \%$ [75]. In the same study combining BDG with LDH, enhanced sensitivity (97\%) but specificity was compromised (72\%). The absence of an organism-specific assay compromises confidence in these strategies, and incorporation of a Pneumocystis-specific PCR is required. Consequently, combining PCR/BDG is preferable to using another non-specific serological biomarker.

Two clinical prediction rules have been developed to diagnose PCP in HIV-positive patients in resource-limited settings [76]. The multivariable models included haemoglobin ( $\geq 9 \mathrm{~g} /$ $\mathrm{dL}$ ), chest radiography typical of PCP, low CD4 count and positive BDG as predictors of PCP in patients with low oxygen saturation $(<94 \%)$ or high respiratory rates $(\geq 30)$. Both the oxygen saturation and respiratory rate predictive rules showed similar performance. Scores of zero excluded PCP and while scores of $\geq 5$ were associated with excellent $L R+$ tive $(>10)$, the probability of PCP was at best $62 \%$ and model sensitivity was $<50 \%$, highlighting the need for the inclusion of sensitive 
Pneumocystis/mycological-specific predictors in the model. As PCP PCR was used as reference test, this was not feasible and BDG was not included in the final model due to its expense [76]. A second multivariable predictive model for PCP in patients with haematological malignancy has been proposed [77]. Variables included chest radiography, lymphoproliferative disease, PCP prophylaxis, and duration of chest symptoms and intensive care unit (ICU) admission. The optimal threshold generated sensitivity and specificity of 87 and $68 \%$, respectively [77]. Together with the previous clinicaldriven HIV-positive model, this highlights the need for the incorporation of specific diagnostics rather than a solely clinical-driven rule-based system.

\section{Management of PCP}

With prevention better than a cure, primary prophylaxis of atrisk patients is beneficial. Systematic review and metaanalysis have shown significant benefit in preventing PCP and reducing PCP-related mortality [78]. With a diverse atrisk population, the absence of guidelines and limited understanding of risk in certain populations (e.g. patients receiving disease-modifying drugs and aggressive chemotherapeutic regimens for inflammatory conditions), all patients do not receive preventative therapy [78-81].

In general, trimethoprim/sulfamethoxazole (TMP/SMX) remains the drug of choice for prophylaxis, with second-line choices considered to provide inferior protection, albeit with potentially fewer side effects. The primary prophylactic agent is one single-strength TMP/SMX (80 mg TMP/400 mg SMX) daily or one double strength tablet $(160 \mathrm{mg}$ TMP/800 mg SMX)/daily [82]. An overview of prophylactic and treatment choices and administration is described in a recent review of PCP [37].

Front-line treatment for PCP, irrespective of underlying condition, is intravenous TMP/SMX (15-20 mg/kg TMP; $75-100 \mathrm{mg} / \mathrm{kg}$ SMX per day) usually for up to 3 weeks, albeit governed by the recovery of the patient. Patients with haematological malignancy and SOT recipients with PCP can be slow to respond and may deteriorate clinically in the first few days of treatment. If there is no clinical improvement after 8 days of therapy, then treatment failure should be considered. Alternative regimens may depend on the severity of disease and the underlying condition, and these factors also determine whether corticosteroids are used [37].

Corticosteroids are beneficial in HIV-infected individuals with severe PCP, their administration associated with reduced mortality, particularly when initiated within $72 \mathrm{~h}$ (i.e. in the early phase of disease) [83]. Given that corticosteroid use may be a risk factor for the SOT patient developing PCP, the use of such therapy as a treatment appears rather conflicting. Generally, there is little evidence to support their use in SOT recipients and the optimal dose is not known [23, 84]. A metaanalysis and systematic review of did not support an association with steroid use and improved survival in SOT recipients $[85,86]$.

With a limited infection control guidance and an ever increasing susceptible population, PCP outbreaks continue to be documented [87••]. Human-to-human transmission is more likely over infection from an environmental source, and sources include PCP cases, prodromal patients and asymptomatic carries, including health-care workers $[87 \bullet \bullet, 88]$. While cross infection from cases in close proximity is an obvious infection control risk, the organism has been detected up to $8 \mathrm{~m}$ from cases, and is more likely in potential 'hyperspreaders', infected with a high fungal burden [89]. Although environmental conditions have been associated with increased rates of PCP, data implying environmental sources of infection is conflicting [87••, 90].

A meta-analysis and systematic review evaluated 30 global PCP outbreaks and associated outbreaks with asymptomatic carriers of Pneumocystis sharing clinical facilities and the de novo development of infection through patient-to-patient transmission [87••]. The confounding factor in most outbreaks is limited, or the absence of PCP prophylaxis [87••]. Effective control of outbreaks is gained through the administration of prophylaxis [19]. Despite the lack of formal international guidelines, patients diagnosed with PCP should not share facilities with other immunocompromised patients [82]. The meta-analysis of Yiannakis and Boswell provides excellent guidelines on outbreak management [87••].

\section{Resistant Disease}

Management of PCP is being increasingly complicated by the emergence of resistant disease. Mutations in dihydrofolate reductase (DHFR) and dihydropteroate synthase (DHPS) infer resistance to TMP/SMX, and the A144V mutation in cytochrome $b$ has been associated with resistance to atovaquone [91, 92]. Determination of resistance is difficult with the lack of PCP culture excluding in vitro susceptibility testing. Direct molecular detection of resistance mutations in genes encoding the enzymes targeted by PCP therapy is the optimal diagnostic approach, and the development of real-time PCR assays has significantly improved turn-around time compared to sequence-based identification [8]. Nevertheless, low fungal burdens, occasionally encountered in HIV-negative patients can even limit the applicability of PCR-based detection. Rates of mutation can vary and their presence is not definitively associated with treatment failure [92, 93]. Inter-human transmission may be predictor for rates of DHPS mutations in PCP sulfa-naïve patients, and together with less stringent case isolation and prophylaxis regimens lead to higher rates of resistant disease [93-95]. 
Currently, there is no guidance on the management of patients where mutations-associated with resistance have been identified; the decision to change therapy should be made on an individual case basis.

\section{Considerations in Paediatric Patients}

Children are exposed to Pneumocystis at a young age; yet in the immuno-competent host, infection is generally asymptomatic or self-limiting. In HIV-positive children, PCP is a common AIDS-defining illness usually in the first year of life [96]. Outside the HIV-positive cohort, PCP is rare, even in those receiving long-term steroid therapy (0.53-0.61 per 10,000 patient yeas) [97]. The use of TMP/SMX prophylaxis in patients receiving steroids for complications in conditions other than HIV, cancer and transplant has to be balanced against the risk for cutaneous hypersensitivity reactions and myelosuppression [97]. As in adults, transmission is usually human-to-human, and low CD4 count is a major risk factor to disease. Clinical presentation varies, but includes fever, tachypnea, dyspnoea, hypoxia and cough, while extra-pulmonary disease is rare [96]. Diagnosis can be made on clinical grounds (CD4 <200 cells/ $\mathrm{mm}^{3}$, low arterial $\mathrm{O}_{2}$, raised $\mathrm{LDH}$ ) combined with radiology, preferably CT, where bilateral diffuse patchy ground glass opacification and thickening of the interlobular septa may be demonstrated. Chest radiograph findings include bilateral perihilar interstitial infiltrates, consolidations, nodules, cavities, pneumothorax and pneumomediastinum, but findings can be unilateral and radiographs can be normal in appearance [98•].

Definitive diagnosis requires the demonstration of the organisms in respiratory tissue or fluid, usually using monoclonal IF antibody staining. BAL fluid remains the preferred specimen [96]. The use of other tests has received only limited validation in the paediatric scenario.

As with PCP in the adult population, TMP/SMX is the recommended choice for both prophylaxis and treatment. Prophylaxis with TMP/SMX is recommended for HIV-positive infants with low CD4 counts or those at risk from maternal HIV transmission [96]. Primary treatment duration with TMP/SMX is 21 days [96]. Short courses of corticosteroids are recommended for the management of PCP in HIV-positive children, but dose varies between studies [96].

Improvements in temperature, respiratory rate, arterial $\mathrm{O}_{2}$ saturation and chest radiology are expected between 5 and 7 days, with clinical deterioration possible in the first 3-5 days. If no clinical improvement is evident or symptoms worsen after 4-8 days of therapy, treatment failure or secondary infection is to be considered.

\section{Concluding Remarks}

The incidence of PCP is increasing in an ever-diverse at-risk population, which, in certain cohorts, has clinical implications due to lack of awareness and limited guidance in relation to the use of prophylaxis and infection control. The continued documentation of PCP outbreaks, most likely through humanto-human transmission, demands up-to-date infection control and outbreak management guidance. With the incorporation of PCR and BDG, diagnosis of PCP is relatively easy to achieve, and combination testing negates the need for invasive sampling. Molecular diagnostics can identify genetic markers of resistance, although the impact of resistance on clinical outcome is yet to be established. The development of clinical prediction rules, should they incorporate mycological diagnostics, could provide individualized patient management.

\section{Compliance with Ethical Standards}

Conflict of Interest $\quad$ P. Lewis White served on an advisory board for F2G and Gilead; received speakers' honoraria from Gilead, MSD and BOPA; received funding for travel and meeting attendance from Gilead, Launch Diagnostics, BOPA and Bruker Diagnostics; received research funding from Bruker Diagnostics; received payment from F2G for providing diagnostic services and is a founding member of the European Aspergillus PCR initiative. Jessica Price and Matthijs Backx declare no conflicts of interest relevant to this manuscript.

Human and Animal Rights and Informed Consent This article does not contain any studies with human or animal subjects performed by any of the authors.

\section{References}

Papers of particular interest, published recently, have been highlighted as:

- Of importance

•- Of major importance

1. Maini R, Henderson KL, Sheridan EA, Lamagni T, Nichols G, Delpech V, et al. Increasing Pneumocystis pneumonia, England, UK, 2000-2010. Emerg Infect Dis. 2013;19(3):386-92. https:// doi.org/10.3201/eid1903.121151.

2. Patterson L, Coyle P, Curran T, Verlander NQ, Johnston J. Changing epidemiology of Pneumocystis pneumonia, Northern Ireland, UK and implications for prevention, 1 July 2011-31 July 2012. J Med Microbiol. 2017;66:1650-165. https://doi.org/ 10.1099/jmm.0.000617.

3. Pegorie M, Denning DW, Welfare W. Estimating the burden of invasive and serious fungal disease in the United Kingdom. J Inf Secur. 2016. https://doi.org/10.1016/j.jinf.2016.10.005.

4. Buchacz K, Lau B, Jing Y, Bosch R, Abraham AG, et al. Incidence of AIDS-defining opportunistic infections in a multicohort analysis of HIV-infected persons in the United States and Canada, 20002010. J Infect Dis. 2016;214:862-72. https://doi.org/10.1093/ infdis/jiw085. 
5. Williams KM, Ahn KW, Chen M, Aljurf MD, Agwu AL, et al. The incidence, mortality and timing of Pneumocystis jiroveci pneumonia after hematopoietic cell transplantation: a CIBMTR analysis. Bone Marrow Transplant. 2016;51:573-80. https://doi.org/10. 1038/bmt.2015.316.

6. Avino LJ, Naylor SM, Roecker AM. Pneumocystis jirovecii pneumonia in the non-HIV infected population. Ann Pharmacother. 2016;50:673-9. https://doi.org/10.1177/1060028016650107.

7. Iriat X, Challan Belval T, Fillaux J, et al. Risk factors of Pneumocystis pneumonia in solid organ transplant recipients in the era of the common use of posttransplantation prophylaxis. Am J Transplant. 2015;15:190-9. https://doi.org/10.1111/ajt. 12947.

8. Montesinos I, Delforge ML, Ajjaham F, Brancart F, Hites M, Jacobs F, et al. Evaluation of a new commercial real-time PCR assay for diagnosis of Pneumocystis jirovecii pneumonia and identification of dihydropteroate synthase (DHPS) mutations. Diagn Microbiol Infect Dis. 2017;87(1):32-6. https://doi.org/10.1016/j. diagmicrobio.2016.10.005.

9. Hay J, Osmond D, Jacobson M. Projecting the medical costs of AIDS and ARC in the United States. J Aquir Immune Defic Syndr. 1988;1(5):466-85.

10. Salzer HJF, Schäfer G, Hoenigl M, Günther G, Hoffmann C, Kalsdorf B, et al. Clinical, diagnostic, and treatment disparities between HIV-infected and non-HIV-infected immunocompromised patients with Pneumocystis jirovecii pneumonia. Respiration. 2018;96(1):52-65. https://doi.org/10.1159/000487713.

11. Oladele R, Otu A, Richardson M, Denning D. Diagnosis and management of Pneumocystis pneumonia in resource-poor settings. J Health Care Poor Undeserved. 2018;29(1):107-58. https://doi.org/ 10.1353/hpu.2018.0010.

12. Lee HY, Choi SH, Kim T, Chang J, Kim SH, Lee SO, et al. Epidemiologic trends and clinical features of Pneumocystis jirovecii pneumonia in non-HIV patients in a tertiary-care hospital in Korea over a 15-year-period. Jpn J Infect Dis. 2019. https://doi. org/10.7883/yoken.JJID.2018.400.

13. Wolfe RM, Peacock JE Jr. Pneumocystis pneumonia and the rheumatologist: which patients are at risk and how can PCP be prevented? Curr Rheumatol Rep. 2017;19:35. https://doi.org/10. 1007/s11926-017-0664-6.

14. Alexandre K, Ingen-Housz-Oro S, Versini M, Sailler L, Benhamou Y. Pneumocystis jirovecii pneumonia in patients treated with rituximab for systemic diseases: report of 11 cases and review of the literature. Eur J Intern Med. 2018;50:e23-4. https://doi.org/10. 1016/j.ejim.2017.11.014.

15. Amber K, Lamberts A, Solimani F, Agnoletti A, Didona D, Euverman I, et al. Determining the incidence of Pneumocystis pneumonia in patients with autoimmune blistering diseases not receiving routine prophylaxis. JAMA Dermatol. 2017;153(11): 1137. https://doi.org/10.1001/jamadermatol.2017.2808.

16. Szydłowicz M, Jakuszko K, Szymczak A, Piesiak P, Kowal A, Kopacz Ż, et al. Prevalence and genotyping of Pneumocystis jirovecii in renal transplant recipients - preliminary report. Parasitol Res. 2018;118(1):181-9. https://doi.org/10.1007/s00436018-6131-0.

17. Neofytos D, Hirzel C, Boely E, Lecompte T, Khanna N, Mueller N, et al. Pneumocystis jirovecii pneumonia in solid organ transplant recipients: a descriptive analysis for the Swiss Transplant Cohort. Transpl Infect Dis. 2018;20(6):e12984. https://doi.org/10.1111/tid. 12984.

18. Redjoul R, Robin C, Foulet F, Leclerc M, Beckerich F, Cabanne L, et al. Pneumocystis jirovecii pneumonia prophylaxis in allogeneic hematopoietic cell transplant recipients: can we always follow the guidelines? Bone Marrow Transplant. 2018. https://doi.org/10. 1038/s41409-018-0391-2.
19. Maschmeyer G, Helweg-Larsen J, Pagano L, Robin C, Cordonnier C, Schellongowski P. 6th European Conference on Infections in Leukemia (ECIL-6), a joint venture of The European Group for Blood and Marrow Transplantation (EBMT), The European Organization for Research and Treatment of Cancer (EORTC), the International Immunocompromised Host Society (ICHS) and The European LeukemiaNet (ELN). ECIL guidelines for treatment of Pneumocystis jirovecii pneumonia in non-HIV-infected haematology patients. J Antimicrob Chemother. 2016;71(9): 2405-13. https://doi.org/10.1093/jac/dkw158.

20. Shimada K, Yokosuka K, Nunokawa T, Sugii S. Differences in clinical Pneumocystis pneumonia in rheumatoid arthritis and other connective tissue diseases suggesting a rheumatoid-specific interstitial lung injury spectrum. Clin Rheumatol. 2018;37(8):2269-74. https://doi.org/10.1007/s10067-018-4157-4.

21. Miller RF, Le Noury J, Corbett EL, et al. Pneumocystis carinii infection: current treatment and prevention. J Antimicrob Chemother. 1996;37(Suppl B):33-53. https://doi.org/10.1093/jac/ 37.suppl_b.33.

22. White PL, Backx M, Barnes RA. Diagnosis and management of Pneumocystis jirovecii infection. Expert Rev Anti-Infect Ther. 2017;15(5):435-47. https://doi.org/10.1080/14787210.2017. 1305887.

23. Iriart X, Bouar ML, Kamar N, Berry A. Pneumocystis pneumonia in solid-organ transplant recipients. J Fungi (Basel). 2015;1(3):293331. https://doi.org/10.3390/jof1030293.

24. Liu Y, Su L, Jiang SJ, Qu H. Risk factors for mortality from Pneumocystis carinii pneumonia (PCP) in non-HIV patients: a meta-analysis. Oncotarget. 2017;8(35):59729-39. https://doi.org/10. 18632/oncotarget. 19927.

25. Lee E, Kim E, Lee S, Roh Y, Leem A, Song J, et al. Risk factors and clinical characteristics of Pneumocystis jirovecii pneumonia in lung cancer. Sci Rep. 2019;9(1):2094. https://doi.org/10.1038/s41598019-38618-3.

26. Garg N, Jorgenson M, Descourouez J, Saddler C, Parajuli S, Astor $\mathrm{B}$, et al. Pneumocystis jiroveci pneumonia in kidney and simultaneous pancreas kidney transplant recipients in the present era of routine post-transplant prophylaxis: risk factors and outcomes. BMC Nephrol. 2018;19(1):332. https://doi.org/10.1186/s12882018-1142-8.

27. Fei MW, Kim EJ, Sant CA, et al. Prediciting mortality from HIVassociated Pneumocystis pneumonia at illness presentation: an observational cohort study. Thorax. 2009;64:1070-6. https://doi.org/ 10.1136/thx.2009.117846.

28. Weng L, Huang X, Chen L, Feng LQ, Jiang W, Hu XY, et al. Prognostic factors for severe Pneumocystis jiroveci pneumonia of non-HIV patients in intensive care unit: a bicentric retrospective study. BMC Infect Dis. 2016;16(1):528. https://doi.org/10.1186/ s12879-016-1855-x.

29. Mu X-D, Jia P, Gao L, et al. Relationship between radiological stages and prognoses of Pneumocystis pneumonia in non-AIDS immunocompromised patients. Chin Med J. 2016;129(17):2020 5. https://doi.org/10.4103/0366-6999.189068.

30. She W, Chok K, Li I, Ma K, Sin S, Dai W, et al. Pneumocystis jirovecii-related spontaneous pneumothorax, pneumomediastinum and subcutaneous emphysema in a liver transplant recipient: a case report. BMC Infect Dis. 2019;19(1):66. https://doi.org/10.1186/ s12879-019-3723-y.

31. Vogel MN, Brodoefel H, Hierl T, Beck R, Bethge WA, Claussen $\mathrm{CD}$, et al. Differences and similarities of cytomegalovirus and Pneumocystis pneumonia in HIV-negative immunocompromised patients thin section CT morphology in the early phase of the disease. Br J Radiol. 2007;80(955):516-23. https://doi.org/10.1259/ bjr/39696316.

32. Hidalgo A, Falcó V, Mauleón S, Andreu J, Crespo M, Ribera E, et al. Accuracy of high-resolution CT in distinguishing between 
Pneumocystis carinii pneumonia and non-Pneumocystis carinii pneumonia in AIDS patients. Eur Radiol. 2003;13(5):1179-84. https://doi.org/10.1007/s00330-002-1641-6.

33. Taeb A, Sill J, Derber C, Hooper M. Nodular granulomatous Pneumocystis jiroveci pneumonia consequent to delayed immune reconstitution inflammatory syndrome. Int J STD AIDS. 2018;29(14):1451-3. https://doi.org/10.1177/0956462418787603.

34. Tokuda H, Sakai F, Yamada H, Johkoh T, Imamura A, Dohi M, et al. Clinical and radiological features of Pneumocystis pneumonia in patients with rheumatoid arthritis, in comparison with methotrexate pneumonitis and Pneumocystis pneumonia in acquired immunodeficiency syndrome: a multicenter study. Intern Med. 2008;47(10):915-23. https://doi.org/10.2169/internalmedicine.47. 0702 .

35. Block B, Mehta T, Ortiz G, Ferris S, Vu T, Huang L, et al. Unusual radiographic presentation of Pneumocystis pneumonia in a patient with AIDS. Case Rep Infect Dis. 2017:3183525. https://doi.org/10. 1155/2017/3183525

36. Cereser L, Dallorto A, Candoni A, Volpetti S, Righi E, Zuiani C, et al. Pneumocystis jirovecii pneumonia at chest high-resolution computed tomography (HRCT) in non-HIV immunocompromised patients: spectrum of findings and mimickers. Eur J Radiol. 2019;116:116-27. https://doi.org/10.1016/j.ejrad.2019.04.025 Excellent summary of the typical PcP chest radiology in HIVnegative, important given the increasing incidence of disease in this cohort.

37. White PL, Price JS, Backx M. Therapy and management of Pneumocystis jirovecii Infection. J Fungi (Basel). 2018;4(4): E127. https://doi.org/10.3390/jof4040127.

38. Karageorgopoulos DE, Qu JM, Korbila IP, Zhu YG, Vasileiou VA, Falagas ME. Accuracy of $b$-D-glucan for the diagnosis of Pneumocystis jirovecii pneumonia: a meta-analysis. Clin Microbiol Infect. 2013;19(1):39-49. https://doi.org/10.1111/j. 1469-0691.2011.03760.x

39. Onishi A, Sugiyama D, Kogata Y, Saegusa J, Sugimoto T, Kawano $S$, et al. Diagnostic accuracy of serum 1,3- $\beta$-DGlucan for Pneumocystis jiroveci pneumonia, invasive Candidiasis, and invasive Aspergillosis: systematic review and meta-Analysis. J Clin Microbiol. 2012;50(1):7-15. https://doi.org/10.1128/JCM.05267-11.

40. Li WJ, Guo YL, Liu TJ, Wang K, Kong JL. Diagnosis of pneumocystis pneumonia using serum (1-3)- $\beta$-D-Glucan:a bivariate meta-analysis and systematic review. Thorac Dis. 2015;7(12): 2214-25. https://doi.org/10.3978/j.issn.2072-1439.2015.12.27.

41. Summah H, Zhu Y-G, Falagas ME, Vouloumanou EK, Qu J-M. Use of real-time polymerase chain reaction for the diagnosis of Pneumocystis pneumonia in immunocompromised patients: a meta-analysis. Chin Med J. 2013;126:1965-73.

42. Fan L-C, Lu H-W, Cheng K-B, Li H-P, Xu J-F. Evaluation of PCR in bronchoalveolar lavage fluid for diagnosis of Pneumocystis jirovecii pneumonia: a bivariate meta-analysis and systematic review. PLoS One. 2013;8:e73099. https://doi.org/10.1371/journal. pone.0073099.

43. Lu Y, Ling G, Qiang C, Ming Q, Wu C, Wang K, et al. PCR Diagnosis of Pneumocystis pneumonia: a bivariate meta-analysis. J Clin Microbiol. 2011;49:4361-3. https://doi.org/10.1128/JCM. 06066-11.

44. White PL, Wingard JR, Bretagne S, Löffler J, Patterson TF, Slavin $\mathrm{MA}$, et al. Aspergillus polymerase chain reaction: systematic review of evidence for clinical use in comparison with antigen testing. Clin Infect Dis. 2015;61(8):1293-303. https://doi.org/10.1093/cid/ civ507.

45. Vogel MN, Weissgerber P, Goeppert B, et al. Accuracy of serum LDH elevation for the diagnosis of Pneumocystis jiroveci pneumonia. Swiss Med Wkly. 2011;141:w13184. https://doi.org/10.4414/ smw.2011.13184.
46. Deng C, Li Y, Li Y. Systemic review: the accuracy of lactic dehydrogenase in the diagnosis of Pneumocystis pneumonia. Zhonghua Wei Zhong Bing Ji Jiu Yi Xue. 2018;30(4):322-6. https://doi.org/ 10.3760/cma.j.issn.2095-4352.2018.04.007.

47. Nyamande K, Lalloo UG. Serum procalcitonin distinguishes CAP due to bacteria, Mycobacterium tuberculosis and PJP. Int J Tuberc Lung Dis. 2006;10:510-5.

48. Mendelson F, Griesel R, Tiffin N, Rangaka M, Boulle A, Mendelson $\mathrm{M}$, et al. C-reactive protein and procalcitonin to discriminate between tuberculosis, Pneumocystis jirovecii pneumonia, and bacterial pneumonia in HIV-infected inpatients meeting WHO criteria for seriously ill: a prospective cohort study. BMC Infect Dis. 2018;18(1):399. https://doi.org/10.1186/s12879-0183303-6.

49. Schildgen V, Mai S, Khalfaoui S, et al. Pneumocystis jiroveci can be productively cultured in differentiated $\mathrm{CuFi}-8$ airway cells. mBio. 2014;5(3):e01186-14. https://doi.org/10.1128/ mBio.01186-14.

50. Liu Y, Fahle GA, Kovacs JA. Inability to culture Pneumocystis jirovecii. MBio. 2018;9(3):e00939-18. https://doi.org/10.1128/ mBio.00939-18

51. Alanio A, Hauser PM, Lagrou K, Melchers WJ, Helweg-Larsen J, Matos O, et al. ECIL guidelines for the diagnosis of Pneumocystis jirovecii pneumonia in patients with haematological malignancies and stem cell transplant recipients. J Antimicrob Chemother. 2016;71(9):2386-96. https://doi.org/10.1093/jac/dkw156 Provides a well thought diagnostic algorithm using both invasive and non-invasive samples that is applicable to all patient populations.

52. Cruciani M, Marcati $\mathrm{P}$, Malena $\mathrm{M}$, et al. Meta-analysis of diagnostic procedures for Pneumocystis carnii pneumonia in HIV-1-infected patients. Eur Respir J. 2002;20:982-9.

53. Guegan H, Robert-Gangneux F. Molecular diagnosis of Pneumocystis pneumonia in immunocompromised patients. Curr Opin Infect Dis. 2019;32(4):314-21. https://doi.org/10.1097/ QCO.0000000000000559 Excellent overview of the molecular diagnosis of $\mathrm{PcP}$, the likely future reference method for diagnosis.

54. Fraczek M, Ahmad S, Richardson M, Kirwan M, Bowyer P, Denning D, et al. Detection of Pneumocystis jirovecii by quantitative real-time PCR in oral rinses from Pneumocystis pneumonia asymptomatic human immunodeficiency virus patients. J Mycol Méd. 2019;29(2):107-11. https://doi.org/10.1016/j.mycmed.2019. 04.001 .

55. Wang M, Dai X, Huang Y, Sun J, Dong X, Guo Y, et al. The presence of Pneumocystis jirovecii DNA in plasma is associated with a higher mortality rate in patients with AIDS-associated Pneumocystis pneumonia. Med Mycol. 2018. https://doi.org/10. 1093/mmy/myy110.

56. Choi J, Lee S, Leem A, Song J, Kim S, Chung K, et al. Pneumocystis jirovecii pneumonia (PCP) PCR-negative conversion predicts prognosis of HIV-negative patients with PCP and acute respiratory failure. PLoS One. 2018;13(10):e0206231. https://doi.org/10.1371/journal.pone.0206231.

57. Roger PM, Vandenbos F, Pugliese P, De Salvador F, Durant J, Le Fichoux Y, et al. Persistence of Pneumocystis carinii after effective treatment of $P$. carinii pneumonia is not related to relapse or survival among patients infected with human immunodeficiency virus infection. Clin Infect Dis. 1998;26(2):509-10. https://doi.org/10.1086/ 517099.

58. Matsumura Y, Tsuchido Y, Yamamoto M, Nakano S, Nagao M. Development of a fully automated PCR assay for the detection of Pneumocystis jirovecii using the GENECUBE system. Med Mycol. 2018. https://doi.org/10.1093/mmy/myy 145 .

59. Sasso M, Chastang-Dumas E, Bastide S, Alonso S, Lechiche C, Bourgeois N, et al. Performances of four real-time PCR assays for 
the diagnosis of Pneumocystis jirovecii Pneumonia. J Clin Microbiol. 2016;54:625-30. https://doi.org/10.1128/JCM.0287615.

60. Lee CH, Helweg-Larsen J, Tang X, Jin S, Li B, Bartlett MS, et al. Update on Pneumocystis carinii f. sp. hominis typing based on nucleotide sequence variations in internal transcribed spacer regions of rRNA genes. J Clin Microbiol. 1998;36(3):734-41.

61. Lu JJ, Lee CH. Pneumocystis pneumonia. J Formos Med Assoc. 2008;107(11):830-42. https://doi.org/10.1016/S0929-6646(08) 60199-0.

62. Alanio A, Gits-Muselli M, Mercier-Delarue S, Dromer F, Bretagne S. Diversity of Pneumocystis jirovecii during Infection revealed by ultra-deep pyrosequencing. Front Microbiol. 2016;7:733. https:// doi.org/10.3389/fmicb.2016.00733.

63. Gits-Muselli M, Peraldi MN, de Castro N, Delcey V, Menotti J, Guigue N, et al. New short tandem repeat-based molecular typing method for Pneumocystis jirovecii reveals intrahospital transmission between patients from different wards. PLoS One. 2015;10(5):e0125763. https://doi.org/10.1371/journal.pone. 0125763

64. Friedrich R, Rappold E, Bogdan C, Held J. Comparative analysis of the Wako $\beta$-Glucan test and the Fungitell assay for diagnosis of Candidemia and Pneumocystis jirovecii Pneumonia. J Clin Microbiol. 2018;56(9):e00464-18. https://doi.org/10.1128/JCM. 00464-18.

65. Mercier T, Guldentops E, Patteet S, Beuselinck K, Lagrou K, Maertens J. Beta-D-Glucan for diagnosing Pneumocystis pneumonia: a direct comparison between the Wako $\beta$-Glucan assay and the Fungitell assay. J Clin Microbiol. 2019;57(6):e00322-19. https:// doi.org/10.1128/JCM.00322-19.

66. White PL, Posso R, Gorton R, Price J, Wey E, Barnes R. An evaluation of the performance of the Dynamiker ${ }^{\circledR}$ Fungus (1-3)- $\beta$-DGlucan assay to assist in the diagnosis of Pneumocystis pneumonia. Med Mycol. 2018;56(6):778-81. https://doi.org/10.1093/mmy/ myx097.

67. Karageorgopoulos D, Vouloumanou E, Ntziora F, Michalopoulos A, Rafailidis P, Falagas M. B-D-Glucan assay for the diagnosis of invasive fungal infections: a meta-analysis. Clin Infect Dis. 2011;52(6):750-70. https://doi.org/10.1093/cid/ciq206.

68. Damiani C, Le Gal S, Da Costa C, Virmaux M, Nevez G, Totet A. Combined quantification of pulmonary Pneumocystis jirovecii DNA and serum (1-3)- $\beta$-D-glucan for differential diagnosis of pneumocystis pneumonia and Pneumocystis colonisation. J Clin Microbiol. 2013;51:3380-8. https://doi.org/10. 1128/JCM.01554-13.

69. de Boer MG, Gelinck LB, van Zelst BD, van de Sande WW, Willems LN, van Dissel JT, et al. $\beta$-D-glucan and Sadenosylmethionine serum levels for the diagnosis of Pneumocystis pneumonia in HIV-negative patients: a prospective study. J Inf Secur. 2011;62(1):93-100. https://doi.org/10.1016/j. jinf.2010.10.007.

70. Rose SR, Vallabhajosyula S, Velez MG, Fedorko DP, VanRaden MJ, Gea-Banacloche JC, et al. The utility of bronchoalveolar lavage beta-D-glucan testing for the diagnosis of invasive fungal infections. J Inf Secur. 2014;69(3):278-83. https://doi.org/10.1016/j. jinf.2014.04.008.

71. Salerno D, Mushatt D, Myers L, Zhuang Y, de la Rua N, Calderon EJ, et al. Serum and BAL beta-D-glucan for the diagnosis of Pneumocystis pneumonia in HIV positive patients. Respir Med. 2014;108:1688-95. https://doi.org/10.1016/j.rmed.2014.09.017.

72. Rautemaa V, Green HD, Jones AM, Rautemaa-Richardson R. High level of $\beta$-(1,3)-d-glucan antigenaemia in cystic fibrosis in the absence of invasive fungal disease. Diagn Microbiol Infect Dis. 2017;88(4):316-21. https://doi.org/10.1016/j.diagmicrobio.2017. 05.010 .
73. Fritzsche C, Ghanem H, Koball S, Mueller-Hilke B, Reisinger E. High Pneumocystis jirovecii colonization rate among haemodialysis patients. Infect Dis (Lond). 2017;49(2):132-6. https://doi.org/10.1080/23744235.2016.1225980.

74. Esteves F, Lee CH, deSousa B, Badura R, Seringa M, Fernandes C, et al. (1-3)-beta-D-glucan in association with lactate dehydrogenase as biomarkers of Pneumocystis pneumonia (PcP) in HIV-infected patients. Eur J Clin Microbiol Infect Dis. 2014;33(7):1173-80. https://doi.org/10.1007/s10096-014-2054-6.

75. Esteves f CSS, Badura R, de Boer MG, Maltez F, Calderón EJ, van der Reijden TJ, et al. Diagnosis of Pneumocystis pneumonia: evaluation of four serologic biomarkers. Clin Microbiol Infect. 2015;4(379):e1-10. https://doi.org/10.1016/j.cmi.2014.11.025.

76. Maartens G, Stewart A, Griesel R, Kengne A, Dube F, Nicol M, et al. Development of a clinical prediction rule to diagnose Pneumocystis jirovecii pneumonia in the World Health Organization's algorithm for seriously ill HIV-infected patients. S Afr J HIV Med. 2018;19(1):851. https://doi.org/10.4102/ sajhivmed.v19i1.851.

77. Azoulay E, Roux A, Vincent F, Kouatchet A, Argaud L, Rabbat A, et al. A Multivariable prediction model for Pneumocystis jirovecii Pneumonia in hematology patients with acute respiratory failure. Am J Respir Crit Care Med. 2018;198(12):1519-26. https://doi. org/10.1164/rccm.201712-2452OC.

78. Green H, Paul M, Vidal L, et al. Prophylaxis of Pneumocystis pneumonia in immunocompromised non-HIV-infected patients: systematic review and meta-analysis of randomized controlled trials. Mayo Clin Proc. 2007;82:1052-9. https://doi.org/10.4065/82. 9.1052 .

79. Alvarez B, Arcos J, Fernandez-Guerrero ML. Pulmonary infectious diseases in patients with primary immunodeficiency and those treated with biologic immunomodulating agents. Curr Opin Pulm Med. 2011;17:172-9. https://doi.org/10.1097/MCP.0b013e3283455c0b.

80. Baddley JW, Winthrop KL, Chen L, Liu L, Grijalva CG, Delzell E, et al. Non-viral opportunistic infections in new users of tumour necrosis factor inhibitor therapy: results of the SAfety Assessment of Biologic ThERapy (SABER) Study. Ann Rheum Dis. 2014;73: 1942-8. https://doi.org/10.1136/annrheumdis-2013-203407.

81. Park JW, Curtis JR, Moon J, Song YW, Kim S, Lee EB. Prophylactic effect of trimethoprim-sulfamethoxazole for pneumocystis pneumonia in patients with rheumatic diseases exposed to prolonged high-dose glucocorticoids. Ann Rheum Dis. 2018;77(5):644-9. https://doi.org/10.1136/annrheumdis-2017211796.

82. Panel on Opportunistic Infections in HIV-Infected Adults and Adolescents. Guidelines for the prevention and treatment of opportunistic infections in HIV-infected adults and adolescents: recommendations from the Centers for Disease Control and Prevention, the National Institutes of Health, and the HIV Medicine Association of the Infectious Diseases Society of America. Accessed 11/09/ 2018, Page numbers B-1 to B-16.

83. Wang LI, Liang H, Ye LI, Jiang J, Liang B, Huang J. Adjunctive corticosteroids for the treatment of Pneumocystis jiroveci pneumonia in patients with HIV: a meta-analysis. Exp Ther Med. 2016;11(2):683-7. https://doi.org/10.3892/etm.2015.2929.

84. Bollee G, Sarfati C, Thiery G, Bergeron A, de Miranda S, Menotti J, et al. Clinical picture of Pneumocystis jiroveci pneumonia in cancer patients. Chest. 2007;132:1305-10. https://doi.org/10.1378/chest. 07-0223.

85. Lemiale V, Debrumetz A, Delannoy A, Alberti C, Azoulay E. Adjunctive steroid in HIV-negative patients with severe Pneumocystis pneumonia. Respir Res. 2013;14:87. https://doi.org/ 10.1186/1465-9921-14-87.

86. Injean P, Eells SJ, Wu H, McElroy I, Gregson AL, McKinnell JA. A systematic review and meta-analysis of the data behind current recommendations for corticosteroids in non-HIV-related PCP: 
knowing when you are on shaky foundations. Transplant Direct. 2017;3(3):e137. https://doi.org/10.1097/TXD.0000000000000642 Provides up-to-date information on the limitations and risks of using corticosteroids in the HIV-negative patient with PcP.

87.• Yiannakis EP, Boswell TC. Systematic review of outbreaks of Pneumocystis jirovecii pneumonia: evidence that $P$. jirovecii is a transmissible organism and the implications for healthcare infection control. J Hosp Infect. 2016;93(1):1-8. https://doi.org/10.1016/j. jhin.2016.01.018 Extensive review of PcP outbreaks, but also provides much needed infection control and outbreak advice.

88. Miller RF, Ambrose HE, Wakefield AE. Pneumocystis carinii f. sp. hominis DNA in immunocompetent health care workers in contact with patients with P. carinii pneumonia. J Clin Microbiol. 2001;39(11):3877-82. https://doi.org/10.1128/JCM.39.11.38773882.2001.

89. Choukri F, Menotti J, Sarfati C, Lucet JC, Nevez G, Garin YJ, et al. Quantification and spread of Pneumocystis jirovecii in the surrounding air of patients with Pneumocystis pneumonia. Clin Infect Dis. 2010;51(3):259-65. https://doi.org/10.1086/653933.

90. Yazaki H, Goto N, Uchida K, Kobayashi T, Gatanaga H, Oka S. Outbreak of Pneumocystis jiroveci pneumonia in renal transplant recipients: $P$. jiroveci is contagious to the susceptible host. Transplantation. 2009;88(3):380-5. https://doi.org/10.1097/TP. 0b013e3181aed389.

91. Argy N, Le Gal S, Coppée R, Song Z, Vindrios W, Massias L, et al. Pneumocystis Cytochrome b mutants associated with atovaquone prophylaxis failure as the cause of Pneumocystis infection outbreak among heart transplant recipients. Clin Infect Dis. 2018;67(6):9139. https://doi.org/10.1093/cid/ciy154.

92. Suárez I, Roderus L, van Gumpel E, Jung N, Lehmann C, Fätkenheuer G, et al. Low prevalence of DHFR and DHPS mutations in Pneumocystis jirovecii strains obtained from a German cohort. Infection. 2017;45(3):341-7. https://doi.org/10.1007/ s15010-017-1005-4
93. Ponce CA, Chabé M, George C, Cárdenas A, Durán L, Guerrero J, et al. High prevalence of Pneumocystis jirovecii dihydropteroate synthase gene mutations in patients with a first episode of Pneumocystis pneumonia in Santiago, Chile, and clinical response to trimethoprim-sulfamethoxazole therapy. Antimicrob Agents Chemother. 2017;61(2):e01290-16. https://doi.org/10.1128/AAC. 01290-16.

94. Hauser PM, Nahimana A, Taffe P, Weber R, Francioli P, Bille J, et al. Interhuman transmission as a potential key parameter for geographical variation in the prevalence of Pneumocystis jirovecii dihydropteroate synthase mutations. Clin Infect Dis. 2010;51(4): e28-33. https://doi.org/10.1086/655145.

95. Huang L, Beard CB, Creasman J, Levy D, Duchin JS, Lee S, et al. Sulfa or sulfone prophylaxis and geographic region predict mutations in the Pneumocystis carinii dihydropteroate synthase gene. J Infect Dis. 2000;182(4):1192-8. https://doi.org/10.1086/315824.

96. Panel on Opportunistic Infections in HIV-exposed and HIVInfected children. Guidelines for the prevention and treatment of opportunistic infections in HIV-exposed and HIV-Infected children. Department of Health and Human Services. Accessed 11/10/2016, Page numbers W-1 to W-16.

97. Basiaga ML, Ross ME, Gerber JS, Ogdie A. Incidence of Pneumocystis jirovecii and adverse events associated With Pneumocystis prophylaxis in children receiving glucocorticoids. J Pediatr Infect Dis Soc. 2018, 7(4):283-9. https://doi.org/10.1093/ jpids/pix052.

98. Katragkou A, Fisher BT, Groll AH, Roilides E, Walsh TJ. Diagnostic imaging and invasive fungal diseases in children. $\mathrm{J}$ Pediatr Infect Dis Soc. 2017;1(6):S22-31. https://doi.org/10. 1093/jpids/pix055 Good overview of typical paediatric radiology associated with invasive fungal disease.

Publisher's Note Springer Nature remains neutral with regard to jurisdictional claims in published maps and institutional affiliations. 